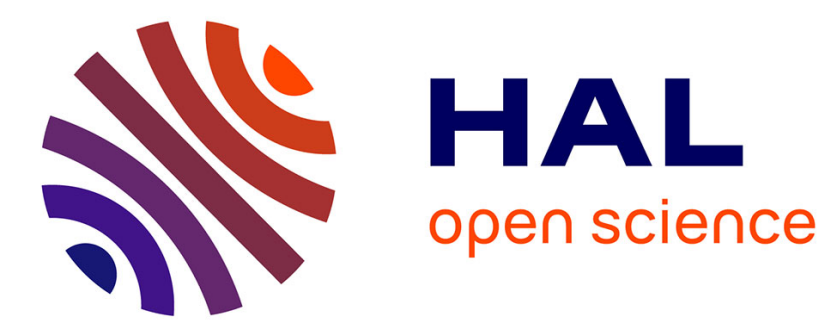

\title{
The Hydrogen Influence upon Oxygen Snoek Relaxation in Nb-Ti Alloys
}

I. Golovin, M. Blanter, A. Vasiliev

\section{To cite this version:}

I. Golovin, M. Blanter, A. Vasiliev. The Hydrogen Influence upon Oxygen Snoek Relaxation in Nb-Ti Alloys. Journal de Physique IV Proceedings, 1996, 06 (C8), pp.C8-107-C8-110. 10.1051/jp4:1996820 . jpa-00254628

\section{HAL Id: jpa-00254628 https://hal.science/jpa-00254628}

Submitted on 1 Jan 1996

HAL is a multi-disciplinary open access archive for the deposit and dissemination of scientific research documents, whether they are published or not. The documents may come from teaching and research institutions in France or abroad, or from public or private research centers.
L'archive ouverte pluridisciplinaire HAL, est destinée au dépôt et à la diffusion de documents scientifiques de niveau recherche, publiés ou non, émanant des établissements d'enseignement et de recherche français ou étrangers, des laboratoires publics ou privés. 


\title{
The Hydrogen Influence upon Oxygen Snoek Relaxation in Nb-Ti Alloys
}

\author{
I.S. Golovin, M.S. Blanter* and A.V. Vasiliev* \\ State Aviation Technology University, Mat. Sci. Dep., Petrovka 27, Moscow 103767, Russia \\ * State Academy of Instrumental Engineering \& Information Science, Strominka 20, Moscow 107846, \\ Russia
}

\begin{abstract}
The oxygen Snoek peak was measured at frequency $\mathrm{f}=1 . .10 \mathrm{~Hz}$ for $\mathrm{Nb}-0.05 \mathrm{wt} \% \mathrm{O}$ and $48 \mathrm{wt} \% \mathrm{Nb}$ $52 w t . \%$ Ti $-0.1 w t . \% O$ alloys. The alloys hydrogenizing leads to the decrease of height and to the shift of the temperature of oxygen Snoek peak for $\mathrm{Nb}-\mathrm{O}$ and $\mathrm{Nb}-\mathrm{Ti}-\mathrm{O}$ alloys both. The new approach for computer simulation of temperature dependent internal friction spectrum has been carricd out for the study of the hydrogen influence mechanism. The following pair interactions have been taken into account: $\mathrm{H}-\mathrm{O}, \mathrm{H}-\mathrm{Ti}, \mathrm{O}-\mathrm{Ti}, \mathrm{H}-\mathrm{H}, \mathrm{O}-\mathrm{O}$. The longranged strain-induced (elastic) interaction model, supplemented by short-range Coulomb repulsion for $\mathrm{H}-\mathrm{H}, \mathrm{H}-\mathrm{O}$, O-O and "chemical" interaction for H-substitutional and O-substitutional atom was used for simulation. The influence of the interaction on atoms arrangement (short-range order), the activation energy and the preexponential factor of oxygen relaxation time was taken into account. It is shown that the infiuence of hydrogen on oxygen Snoek peak can be explained by the influence of hydrogen on energy of oxygen atoms in solid solution and therefore on activation energy of diffusion.
\end{abstract}

\section{INTRODUCTION}

Internal friction (IF) spectra caused by interstitial atoms (IA) diffusion depend on interaction of solute IA with each other and with substitutional atoms $[1,2]$. The situation when substitutional atoms are considered as practically unmoveable at the measured temperature range in comparison with IA is studied rather well. For example, the influence of substitutional atoms on Snoek relaxation in b.c.c. metals or the influence of substitutional atoms and "heavy" IA $(\mathrm{O}, \mathrm{N})$ on Snoek-type hydrogen relaxation in Nb, V, Ta $[1,3]$. In these or similar cases the relaxation spectra could be explained from the viewpoint of interatomic pair interactions.

The situation with influence of mobile IA on diffusion under the stress of "heavy" IA is not enough studied. In particular, this case takes place with the hydrogen influence on oxygen Snoek relaxation in $\mathrm{Nb}$ and $\mathrm{Nb}$-based b.c.c. alloys [9]. Further the goals of this paper are: 1) to study the hydrogen influence on oxygen Snoek relaxation in $\mathrm{Nb}$ and $\mathrm{Nb}-68 \mathrm{at} \% \mathrm{Ti}$ (or $52 \mathrm{wt} \% \mathrm{Ti}$ ); 2) to study the influence of interatomic pair interactions on this effect with the help of computer simulation. Such an investigation seems to be interesting from the viewpoint of mechanism of relaxation as well as from the viewpoint of hydrogen behaviour in real $\mathrm{Ti}-\mathrm{Nb}$ alloy used for hydrogen storage.

\section{EXPERIMENTAL PROCEDURE}

The $\mathrm{Nb}(0.05$ wt. $\%$ or $\sim 0.3$ at. $\% \mathrm{O})$ and $\mathrm{Nb}-\mathrm{Ti}(\sim 0.1$ wt. $\%$ or $\sim 0.4$ at. $\% \mathrm{O})$ samples with $\mathrm{Ti}$ content 68 at. $\%$ have been vacuum melted and drawn into wires of $1 \mathrm{~mm}$ in diameter. The samples were annealed at $1073 \mathrm{~K}$ during 2 hours. Hydrogenizing was carried out at $800{ }^{\circ} \mathrm{C}$. After this heat treatment the concentrations of hydrogen in $\mathrm{Nb}$ were $0.005,0.05 ; 0.09 ; 0.3 \mathrm{wt} \%$ and in $\mathrm{Nb}-\mathrm{Ti}$ that was $0.15 ; 0.22$; $0.47 ; 1.0 \mathrm{wt} \% \mathrm{H}$.

IF measurements were carried out with the use of different low frequency techniques*

1) free decay torsion inverted pendulum "RKM-TPI" ( $f=1-2 \mathrm{~Hz}$ ),

2) forced, computer controlled, torsion inverted pendulum $(1-10 \mathrm{~Hz})$.

All the measurements were performed in vacuum of $6 \cdot 10^{-5}$ Torr or higher with heating-cooling rate 2 $\mathrm{K} / \mathrm{min}$.

\footnotetext{
Experimantal points marked as up triangles in Fig.1 and 2 are measured by E. V. Schinaeva (Mat.Sci.Dep. of MSAT University) using free-decay pendulum; marked as squears in Fig.1 are from [9]; all the other points are authors results, square points in Fig.2 are measured using forced pendulum.
} 


\section{EXPERIMENTAL RESULTS}

The oxygen and nitrogen Snoek peaks are observed at $\sim 425 \mathrm{~K}$ and $\sim 560 \mathrm{~K}(\mathrm{f}=1 \mathrm{~Hz}$ ) in Nb at temperature dependent IF (TDIF) curves. Peak parameters are in good agreement with the results of other researchers [1]. The hydrogen alloying leads to the increase in temperature (Fig. 1,a) and to the decrease in height (Fig. 1, b) of oxygen Snoek peak. Additionally to our experimental points (triangles) the temperatures of oxygen Snoek peak are calculated from activation energies and pre-exponential factors reported by Schmidt and Wipf [9].

Additionally to relaxation peaks the non-relaxation peak connected with hydride transformation is observed in the range of positive temperatures on TDIF curves for samples with $0.05 \mathrm{wt} . \%(4.4$ at. $\%) \mathrm{H}$ and more. This hydride phase transformation peak (HPTP) gives considerable difficulties to study oxygen Snoek peak. For example, the HPTP temperature for sample with $\mathrm{H} / \mathrm{Nb}=0.28$ is $\approx 420 \mathrm{~K}$, which is rather close to the oxygen Snoek peak location. The temperatures of HPTP depend on hydrogen content and coincide well with the solvus line of hydrogen in $\mathrm{Nb}$, its height depends on heating-cooling rate and frequency on the very similar well known IF peak due to martensitic transformation, i.e. $Q^{-1} \sim A / f$ (where $\mathrm{A}=\mathrm{dT} / \mathrm{dt}$ is heating or cooling rate: $\mathrm{T}$ - temperature, $\mathrm{t}$ - time, $\mathrm{f}$ - frequency of oscillations. The HPTH height (nearly $800^{\circ} 10^{-4}$ ) for alloy with $\mathrm{H} / \mathrm{Nb}=0.28$ completely covers oxygen Snoek peak with height $\mathrm{Q}^{-1}<$ $10^{-2}$. That circumstance leads to the increase in mistaken range of experimental data and to the scattering in our experimental data and data calculated from paper [9]. According to our results the oxygen Snoek peak shift in $\mathrm{H} / \mathrm{Nb}=0.1$ is $\approx 10 \mathrm{~K}$, according to [9] that shift is smaller. Nevertheless, the effect is qualitatively similar: hydrogenizing leads to the increase in temperature and to the decrease in height of oxygen relaxation.

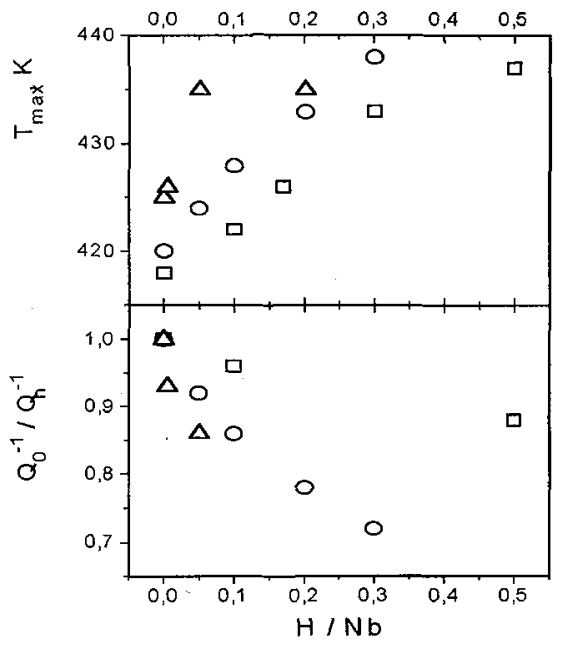

Fig. 1

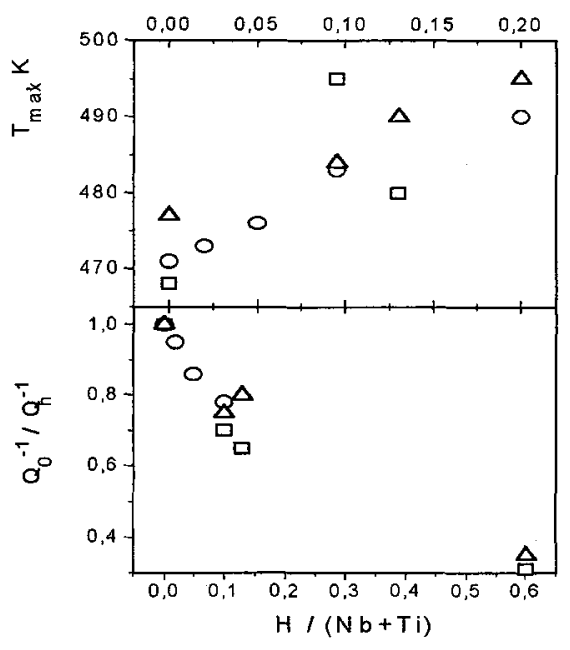

Fig. 2

Figure 1. The influence of hydrogen content on the temperature and relative height of oxygen Snoek peak in $\mathrm{Nb}$; circles results of computer simulation, other - experimental points.

Figure 2. The influence of hydrogen content on the temperature and relative height of oxygen Snoek peak in $\mathrm{Nb}+68 \mathrm{at} . \% \mathrm{Ti}$; circles - results of computer simulation, other - experimental points

The oxygen Snoek peak in Nb-68at.\%Ti is observed at higher temperatures $(468 \mathrm{~K}$ at $1 \mathrm{~Hz}$, or $532 \mathrm{~K}$ at $10 \mathrm{~Hz}$ ) in comparison with pure $\mathrm{Nb}$. It is known that $\mathrm{Nb}$ alloying by $\mathrm{Ti}(1$ at. $\%)$ leads to the additional oxygen peak appearance at the higher temperatures [10] as a result of oxygen jumps in the vicinity of $\mathrm{Ti}$ atoms. The only one relaxation peak takes place in high alloyed $\mathrm{Nb}-68 \mathrm{at} . \% \mathrm{Ti}$. The hydrogenizing increases its temperature (Fig. 2,a) and decreases height (Fig.2,b) in the very similar way as that in $\mathrm{Nb}-\mathrm{O}-\mathrm{H}$ case. The temperature shift is $\approx 10 \mathrm{~K}$ at $\mathrm{H} /(\mathrm{Nb}+\mathrm{Ti})=0.14$ in comparison with hydrogen-free alloy. Additionally to Snoek peak two more peaks are observed $(\mathrm{f}=1 \mathrm{~Hz})$ in the alloy with $0.62(\mathrm{H} / \mathrm{Me})$ : at $\approx 380 \mathrm{~K}$ and $\approx 600 \mathrm{~K}$. The first peak is HPTP, the second one is supposed to be hydride transformation strain-induced peak. These peaks in $\mathrm{Nb}$ and $\mathrm{Nb}-\mathrm{Ti}$ alloys will be reported in the another paper. 


\section{COMPUTER SIMULATION OF INTERNAL FRICTION SPECTRA}

As it is above pointed the increase in relaxation peak temperatures is the result of the activation energies increase due to the additional interaction of moveable atoms with other atoms in solid solution [4-8]. The peculiarity of oxygen relaxation in hydrogenized alloys is the uncertainty of the mechanism of highmoveable hydrogen atoms influence on oxygen atoms diffusion under stress and its activation energy. Computer simulation helps to clarify the situation. Method of simulation is given in details in $[5,6]$.

The following assumptions are made for IF calculations:

1). The long-range interaction $\mathrm{O}-\mathrm{O}, \mathrm{H}-\mathrm{H}, \mathrm{H}-\mathrm{O}, \mathrm{O}-\mathrm{Ti}, \mathrm{H}-\mathrm{Ti}$ affects the arrangement of $\mathrm{O}$ and $\mathrm{H}$ atoms (creates short-range order), changes the energy of $\mathrm{O}$-atoms in octahedral interstices by $\Delta \mathrm{E}_{\mathrm{p}}$ and consequently changes the individual diffusion barrier $H_{p}$ of the p-th oxygen atom: $H_{p}=H_{D}-\Delta E_{p}$ where $H_{D}$ is the activation energy of diffusion of a $\mathrm{O}$-atom in a dilute solid solution of oxygen in $\mathrm{Nb}$.

2). The pre-exponential factor $\tau_{0}$ of the relaxation time $\tau$ is independent of the solute interaction and is equal to $\tau_{\mathbf{0}}$ of the oxygen Snoek peak in $\mathrm{Nb}\left(2,5610^{-15} \mathrm{~s}\right)$.

3) Each $O$ atom has the same relaxation strength $\delta$.

Thus, calculation of the IF has been performed in two stages:

a) Monte Carlo computer simulation of the arrangement of mobile $\mathrm{H}$ and $\mathrm{O}$ atoms in the model crystal with fixed $\mathrm{Ti}$ atoms (Nb-Ti alloy) or without $\mathrm{Ti}$ atoms (pure $\mathrm{Nb}$ ).

$\mathrm{H}_{\mathbf{p}}$ :

b) Determination of the contribution of each $\mathrm{p}$-th $\mathrm{O}$ atom to IF according to its activation energy

$$
\mathrm{Q}^{-1}=(\delta / \mathrm{T}) \cdot \sum_{\mathrm{p}=1}^{\mathrm{N}}\left[\left(\omega \tau_{\mathrm{p}}\right) /\left(1+\left(\omega \tau_{\mathrm{p}}\right)^{2}\right)\right],
$$

where $\tau_{p}=\tau_{0} \exp \left(\mathrm{H}_{\mathrm{p}} / \mathrm{kT}\right), \mathrm{N}$ is the number of $\mathrm{O}$ atoms in the model crystal, $\omega=2 \pi \mathrm{f}$ is the angular frequency of oscillations, $f(=1 \mathrm{~Hz})$ is the frequency of oscillations, $\delta$ is the relaxation strength per one oxygen atom, $\mathrm{T}$ is the temperature, $\mathrm{k}$ is the Boltzman constant.. For simulation of a short-order and determination $\Delta \mathrm{E}_{\mathrm{p}}$ value by Monte Carlo method the energies of pairwise interactions $\mathrm{H}-\mathrm{H}, \mathrm{O}-\mathrm{O}, \mathrm{H}-\mathrm{O}, \mathrm{H}-$ $\mathrm{Ti}$ and $\mathrm{O}-\mathrm{Ti}$ were used. The model of solute interactions is a long-range strain-induced (elastic) interaction supplemented by screened Coulomb interaction in the nearest coordination shells in case of $\mathrm{H}-\mathrm{H}, \mathrm{O}-\mathrm{O}$ and $\mathrm{H}-\mathrm{O}$ interaction and "chemical" interaction in case of O-Ti and $\mathrm{H}-\mathrm{Ti}$ interactions $[4,5,12]$. The elastic energies are calculated for crystalline lattice of $\mathrm{Nb}$ and corrected for $\mathrm{Nb}-\mathrm{Ti}$ alloy according to its elastic constants. "Chemical" part of interaction energy for O-Ti $(-0.15 \mathrm{eV})$ is determined with the help of computer simulation for oxygen Snoek peak in Nb-1at.\%Ti alloy reported in [10]. Energy of "chemical" $\mathrm{H}-\mathrm{Ti}$ interaction $(-0.08 \mathrm{eV})$ is determined using method given in [12] by comparing calculated and experimental values of the activation energy of diffusion [13].

\section{RESULTS OF SIMULATION AND DISCUSSION}

Oxygen Snoek peaks simulated in $\mathrm{Nb}$ with hydrogen content up to 20 at. \% $\mathrm{H}$ are plotted in Fig. 3 . The hydrogen content increase leads to the increase in temperature and to the decrease in height of peak, and coincides rather well with our experimental results (Fig. 1) and results reported in [9]. The same situation takes place for simulated and experimental results in $\mathrm{Nb}$ - $\mathrm{Ti}$ alloy. The scattering of experimental data does not give the opportunity to find out if the influence of hydrogen is stronger or not in the presence of $\mathrm{Ti}$ in solid solution. Computer simulation evidences that the oxygen peak shift due to hydrogen is slightly stronger in alloy containing Ti: $13 \mathrm{~K}$ instead of $7 \mathrm{~K}$ in $\mathrm{Nb}$ for $\mathrm{H} / \mathrm{Me}=0.1$ or $18 \mathrm{~K}$ instead of $13 \mathrm{~K}$ for $\mathrm{H} / \mathrm{Me}=0.2$. 


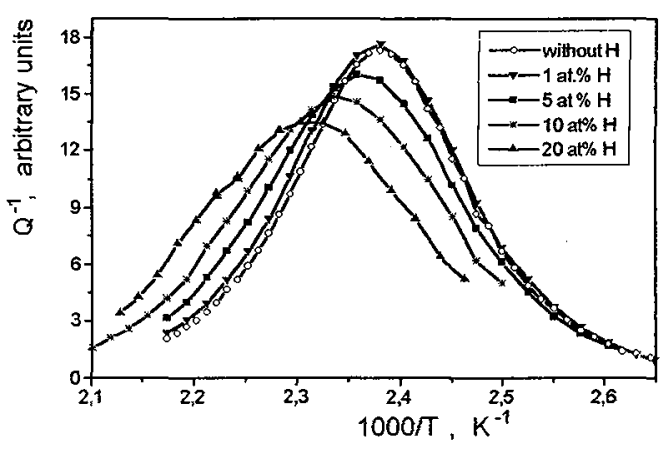

Fig. 3

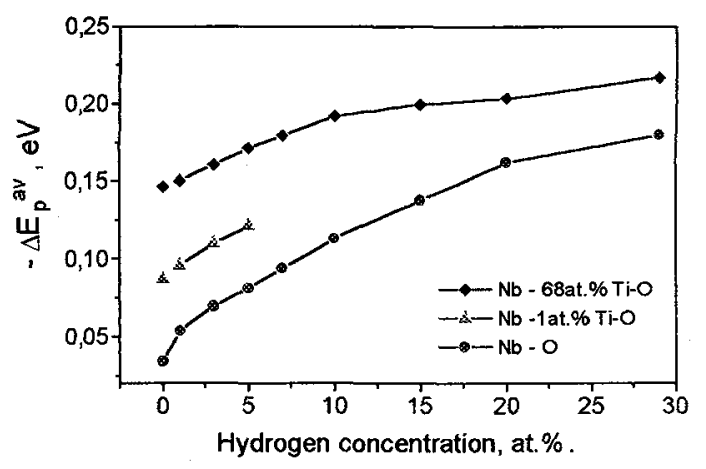

Fig. 4

Figure 3. The hydrogen influence on simulated IF curves for $\mathrm{Nb}$. Figure 4. The influence of $\mathrm{H}$ content and $\mathrm{Ti}$ on $\Delta \mathrm{E}_{\mathrm{p}}$ values

That is connected with the preferable distribution of oxygen and hydrogen atoms in the vicinity of $\mathrm{Ti}$ atoms. The influence of hydrogen is connected with the change of $/ \Delta \mathrm{E}_{\mathbf{p}} /{ }^{\mathrm{av}}$ energy of oxygen atoms due to their interaction with hydrogen and other solute atoms. The titanium increases that effect. Computer simulation predicts the effect saturation due to the increase in hydrogen, which was experimentally observed in [9]. The peak decrease is the result of broadening of $\Delta \mathrm{E}_{p}$ distribution with the increase in hydrogen content. Oxygen atoms with the energies very different from the average values $\Delta \mathrm{E}_{\mathrm{p}}$ do not give contribution to oxygen Snoek peak. To sum up, the computer simulations show that the influence of hydrogen on the parameters of oxygen Snoek peak in. $\mathrm{Nb}$ and b.c.c $\mathrm{Nb}-\mathrm{Ti}$ alloy is qualitatively and quantitatively explained by its elastic interaction with oxygen atoms.

\section{CONCLUSIONS}

1. Hydrogenizing of $\mathrm{Nb}$ and $\mathrm{Nb}-\mathrm{Ti}$ leads to the increase in temperature and energy, and to the decrease in height of the oxygen Snoek peak and to the appearance of new hydride transformation induced internal friction peaks.

2. The hydrogen influence is explained by the interaction of soluted atoms, which leads to the decrease of oxygen atoms energy and to the increase of the activation energy of diffusion in solid solution.

\section{Acknowledgement}

This work was supported by the Russian Fund Fundamental Research under grant N 96-0217389

\section{References}

[1] Blanter M.S., Piguzov Yu. V., Golovin I.S. et al. The method of internal friction in metallurgical research (a reference book), Moscow: Metallurgia, 1991, 246 p. (in Russian).

[2] Nowick A.S., B.S.Berry. Anelastic Relaxation in Crystalline Solids. Acaddemic Press, New York and London, 1972 .

[3] Cannelli G., Cantelli R., Cordero F. et.al. Materials Science Forum. Vol..119-121, (1993), p. 29-38,

[4] Blanter M.S., Fradkov M.Y. Acta Met. et Mat., v.40, p. 2201 (1992).

[5] Blanter M.S. Phys. Rev. B, v. 50, p. 3603, (1994).

[6] Golovin, Blanter, Schaller., to be published

[7] Koiwa M. Phil.Mag., v.24, p. 81, (1971).

[8] Koiwa M. Phil.Mag., v.24, p. 107, (1971).

[9] Schmidt R., Wipf H. Materials Science Forum. Vol.119-121, p.133-138

[10] Szkopiak Z.C. and Smith J.T. J. Phys.D: Appl. Phys., v.8 (1975), p.1273

[11] Blanter M.S., Khachaturyan A.G. Met.Trans. v.9A, p. 753 (1978).

[12] Blanter M.S. and Vasiljev A.V. in.: Stability of Materials (Ed. by A.Gonis et. al.), Plenum Press, 1996, p.211

[13] Cannelli G. and Cantelli R. Proc. of 2-d Congress of Hydrogen in Metals. Paris, Pergamon Press (1977), p.1. 